\title{
Groundwater recharge estimation in semi-arid zone: a study case from the region of Djelfa (Algeria)
}

\author{
S. E. Ali Rahmani ${ }^{1} \cdot$ Brahim Chibane $^{1} \cdot$ Abdelkader Boucefiène $^{2}$
}

Received: 27 July 2015/ Accepted: 21 February 2016/Published online: 8 March 2016

(c) The Author(s) 2016. This article is published with open access at Springerlink.com

\begin{abstract}
Deficiency of surface water resources in semiarid area makes the groundwater the most preferred resource to assure population increased needs. In this research we are going to quantify the rate of groundwater recharge using new hybrid model tack in interest the annual rainfall and the average annual temperature and the geological characteristics of the area. This hybrid model was tested and calibrated using a chemical tracer method called Chloride mass balance method (CMB). This hybrid model is a combination between general hydrogeological model and a hydrological model. We have tested this model in an aquifer complex in the region of Djelfa (Algeria). Performance of this model was verified by five criteria [Nash, mean absolute error (MAE), Root mean square error (RMSE), the coefficient of determination and the arithmetic mean error (AME)]. These new approximations facilitate the groundwater management in semi-arid areas; this model is a perfection and amelioration of the model developed by Chibane et al. This model gives a very interesting result, with low uncertainty. A new recharge class diagram was established by our model to get rapidly and quickly the groundwater recharge value for any area in semi-arid region, using temperature and rainfall.
\end{abstract}

Keywords Groundwater recharge $\cdot$ Hybrid model $\cdot$ Semiarid area $\cdot$ Chloride mass balance $\cdot$ Djelfa

S. E. Ali Rahmani

alirahmani101990@gmail.com

1 Geo-environment Laboratory, FSGAT, USTHB, Bab Ezzouar, Algeria

2 Earth sciences department, University of Djilali Bounaama, Khemis Miliana, Algeria

\section{Introduction}

In semi-arid area, the groundwater resources are the most requested to meet the water to supply population, industrial and agricultural activities. In the world $50 \%$ of drinking water, $40 \%$ of water intended for industrial activities, and $20 \%$ of water for agriculture are groundwater (Foster and Chilton 2003). The daily water needs of the population increases with population growth. Therefore the concepts of sustainable management of water resources become indispensable. For that one of the major problems encountered in the management of groundwater resources is the evaluation of groundwater recharge to quantify groundwater reserves. Groundwater recharge is a difficult parameter; its estimation contains several constraints linked to the topography, the soil, the density of vegetation cover, geological heterogeneity and reliability of hydro-climatic data (Sibanda et al. 2009). Several approaches are followed to quantify this parameter which represents the core of groundwater management.

Reviews of groundwater recharge estimation technique Lot of methods were used in the entire world to quantify the rate of the groundwater recharge, as reported by Kinzelbach et al. (2002) and Osterkamp et al. (1995).

The most used method is the Hydrological water budget (HWB), Chemical tracers [Chloride mass balance (CMB); and isotopic tritium profile method] (Scanlon et al. 2006), and the soil water budget; and the water fluctuation level (WFL) method, Aquifer recharge rate relate directly to the soil texture, rock properties and to the velocity of infiltration and to the intensity of precipitation (Bonta and Müller 1999). Hydrological modeling shows a very rapid progress in the last decade due to the evolution of informatics systems (hard and software).

Limit of estimation of groundwater recharge The previous methods have a limit applications (water level fluctuation methods, Darcyian methods, soil budgets methods, 


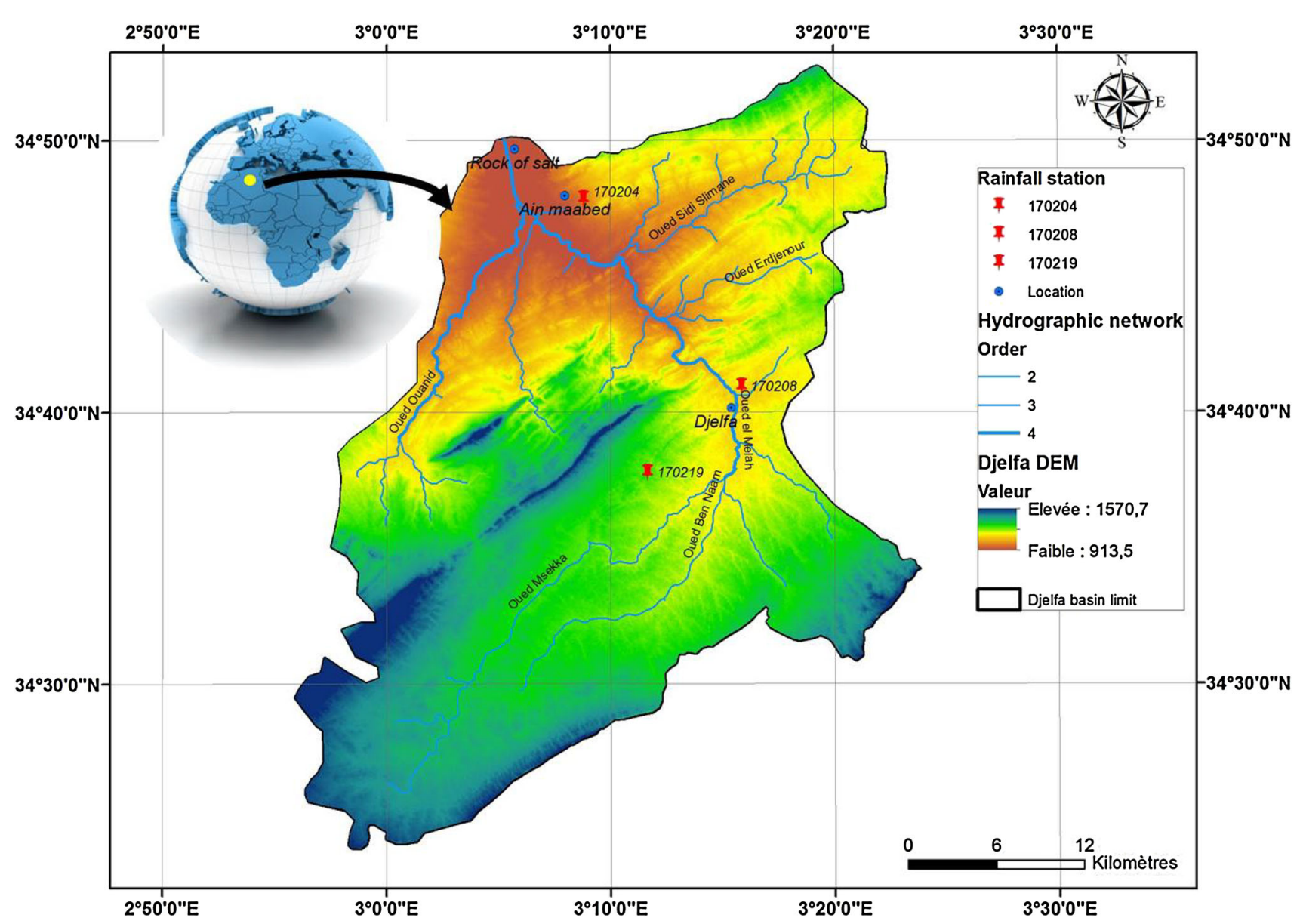

Fig. 1 Study area (Ali Rahmani et al. 2015)

and hydrological modeling) because of many problems in the fields of study: the geological heterogeneous of the study area; high depth of soil (up to $30 \mathrm{~m}$ ), the fracturation density in some cretaceous deposits, and lack of data (water level control wells, spring source discharge, aquifers properties; and soils depth).

The hydrological balance has a high limit of groundwater estimation; this is principally due to the high uncertainty in the estimation of Real evapotranspiration (Turc, Penman, and Thornthwaite) methods. For this problem the model of Chibane et al. was derived to solve these problems. To minimize the high uncertainty in estimation of recharge using the Hydrological water budget (some hydrological balance in semi-arid give a negative balance) which makes estimation of recharge very complicated.

\section{Materials and methods}

In this paper we have combined three methods to evaluate the GWR: using the Chloride mass balance (CMB), a hydrogeological model based on soil and rock characteristic and a new Hybrid model. The combination between these methods lets us to adjust a general model to evaluate with high usefulness and with small error the rate of GWR.

\section{Area of study}

The area of study was located in the South of Algeria $300 \mathrm{~km}$ from Algiers (Capital of Algeria), situated between $34^{\circ} 40^{\prime} 30^{\prime \prime}$ North and $3^{\circ} 15^{\prime} 30^{\prime \prime}$ East (Fig. 1). It is placed between two groups of mountains; in the north we find the Tellian Atlas, in the south the Saharian Atlas (Chibane and Ali-Rahmani 2015).

\section{Geological data}

Our area is formed by different geological deposits, recently we found Mio-plioquaternary deposits, it is formed by Sandy loams and limestone crusts, also by clays and red marl and lenses chalky conglomerate-sandstone. Secondly we find the Santonian deposit is formed alternately by Limestone and marl and frequently by gypsum lenses. Thirdly the Turoniana deposit presents a high 


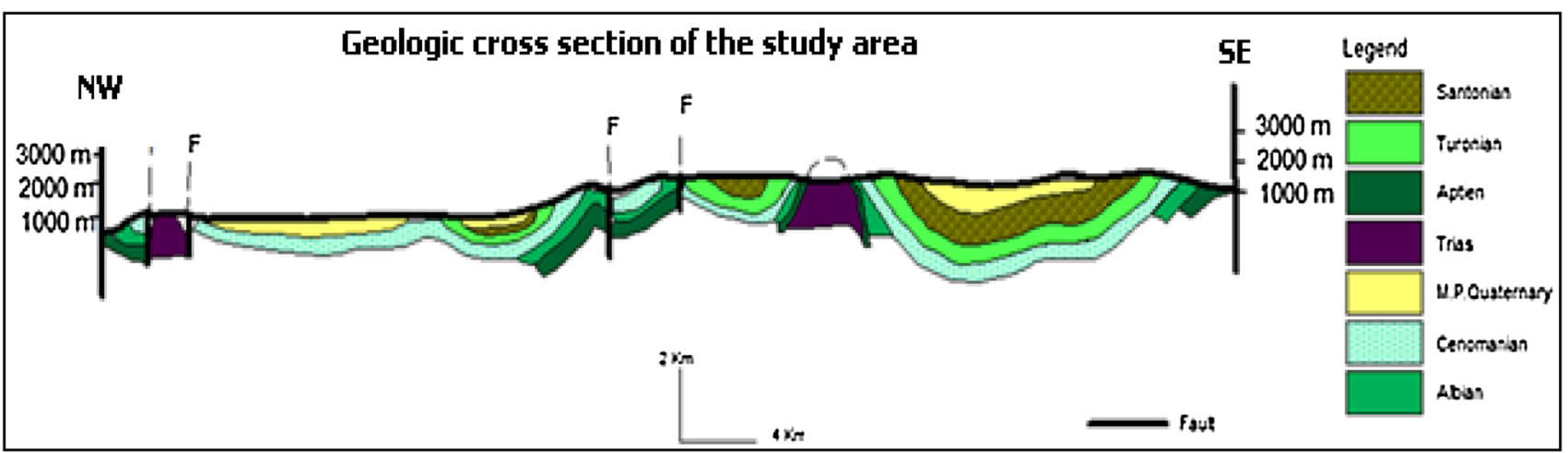

Fig. 2 Geologic cross section of study area (Cornet and Trayssac 1952, modified by Chibane and Ali-Rahmani 2015)

groundwater reservoir and it is formed by benches of Limestone to the top, marl and limestone in the middle part and gypsum at the base. Fourthly the Cenomanian deposits are composed of marl with few limestone and gypsum (Chibane and Ali-Rahmani 2015).

Fifthly we find the Albian deposits divided into two groups: the Upper Albian who has formed alternately by Limestone and marl and the Lower Albian formed by massive fine sandstone intercalated with gray clays. The two groups formed a high capacity reservoir. The next deposit is the Aptian composed alternately from Limestone and Marl. The Barremien was composed of Alternating sandstone and sandstone clay red with a cross-bedded common in sandstone and lot of joints and cracks. The Neo-comian deposits were specified by the presence of Clay sandstone rocksat in the base and dolomite limestone and calcareous sandstone. The Triassic is the last formation it was formed by Clay 'swine-colored sandstone and shale and marl colored with some inclusion conglomerates (Chibane 2010).

Figures 2 and 3 show a geologic cross section of the aquifer of study, and the geological map of the study area.

\section{Hydro-climatic study}

The region of Djelfa is characterized by a semi-aride climate with a cold winter and a warm summer.

The precipitation is moderate in the time and space scale, it varies at average between 300 and $360 \mathrm{~mm} /$ year; the intensity is different from the West to the East and from the North to the south (Chibane 2010) the variation of average monthly temperature and rainfall are given in Fig. 4.

\section{Chloride mass balance}

In many research papers the chloride mass balance method was applicated to evaluate the groundwater recharge in semi-arid area this methods assume that chloride does not have any chemical interaction with soils (Nimmo et al. 2005). This technique has been used in this work to give a reference value of GWR to calibrate the new hybrid model. The chloride is a conservative tracer used in hydrogeological studies; this technique is based on the ratio between the chloride concentration in rainfall and the chloride concentration in groundwater samples.

No previous work in the field of study has used the CMB method. 60 samples of rainfall and Groundwater were collected, prepared and analyzed in the laboratory for the hydrological year (2013/2014).

The GWR is estimated using the equation (Eq. 1):

$\mathrm{GWR}=P \times \frac{[\mathrm{Cl}]_{\mathrm{p}}}{[\mathrm{Cl}]_{\mathrm{gw}}}$

with: $G W R$ recharge in $\mathrm{mm}, P$ average annual rainfall in $\mathrm{mm},[\mathrm{Cl}]_{\mathrm{p}}$ concentration of chloride in precipitation in $\mathrm{mg} /$ $1,[\mathrm{Cl}]_{\mathrm{gw}}$ concentration of chloride in groundwater in $\mathrm{mg} / \mathrm{l}$.

\section{The hydrogeological approach}

The groundwater recharge value was estimated using a hydrogeological model which depends on soil and rock infiltration coefficient. In Table 1 we give the methodology of calcul of GWR using infiltration coefficient $\phi$ the result of variation of recharge using the hydrogeological model shown in Fig. 5.

The equation of this model was given by Eq. (2) as follows:

$\mathrm{GWR}=\frac{\phi \times P}{100}$

We have uniformized the geological coefficient $\phi$ to derive a linear relationship (Eq. 3):

$\mathrm{GWR}=0.034 \times P$ 


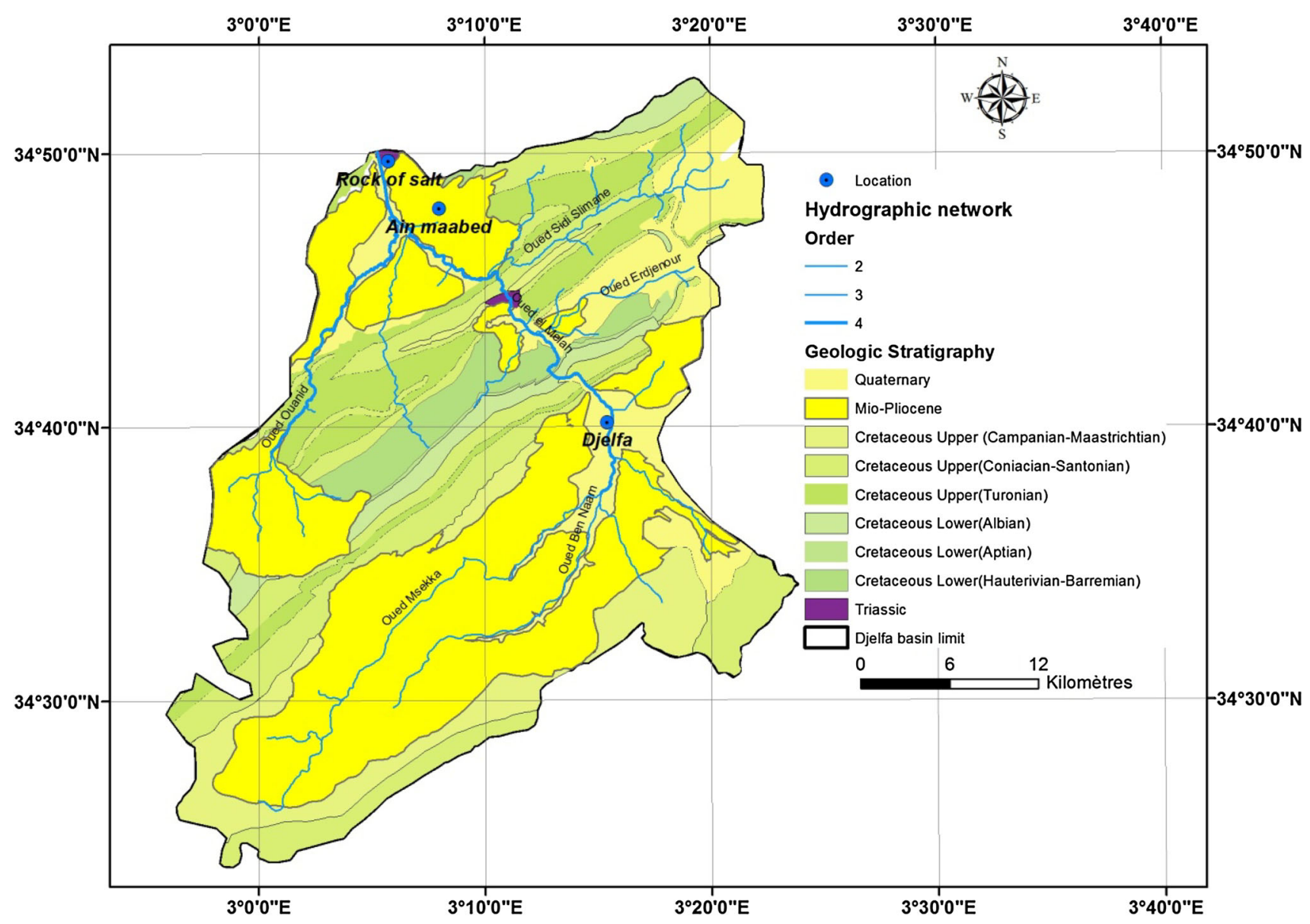

Fig. 3 Geologic Map of study area

Fig. 4 Monthly variation of average temperature and precipitation in the region of Djelfa

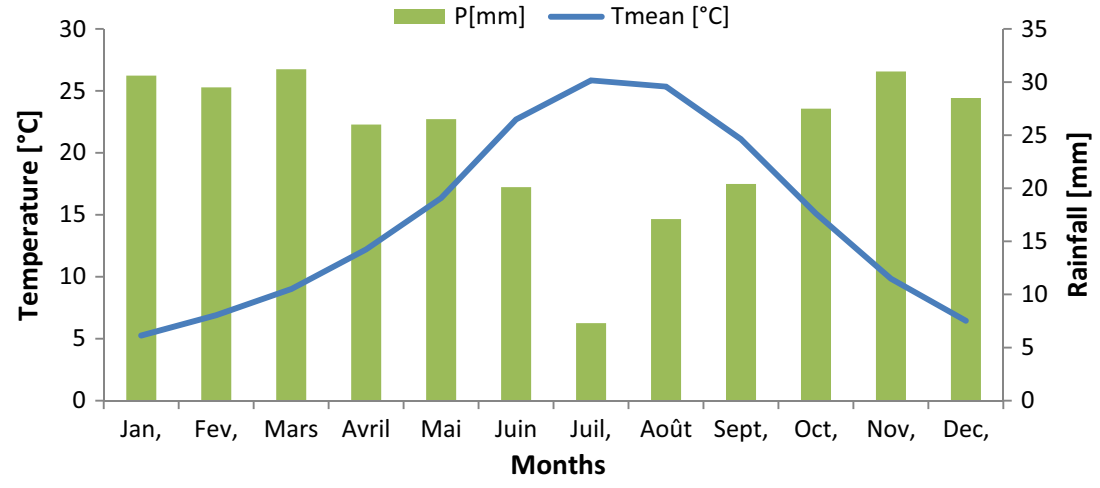

Table 1 Calcul methodology for a given type of Rock

\begin{tabular}{llllll}
\hline iD & Rock & Infiltration coefficient $(\phi)$ & $\begin{array}{l}\text { Rainfall } \\
\text { P (mm) }\end{array}$ & GWR (mm) & Mean GWR (mm) \\
\hline 1 & GRAVELS & 6 & 320 & GWR $=\frac{6.320}{100}=19.2$ & GWR $=\frac{19.2+6.4}{2}=12.8$ \\
2 & Limestone & 2 & 320 & $G W R=\frac{2.320}{100}=6.4$ & \\
\hline
\end{tabular}


Fig. 5 Spatial ground water recharges variation in study region using hydrogeological model

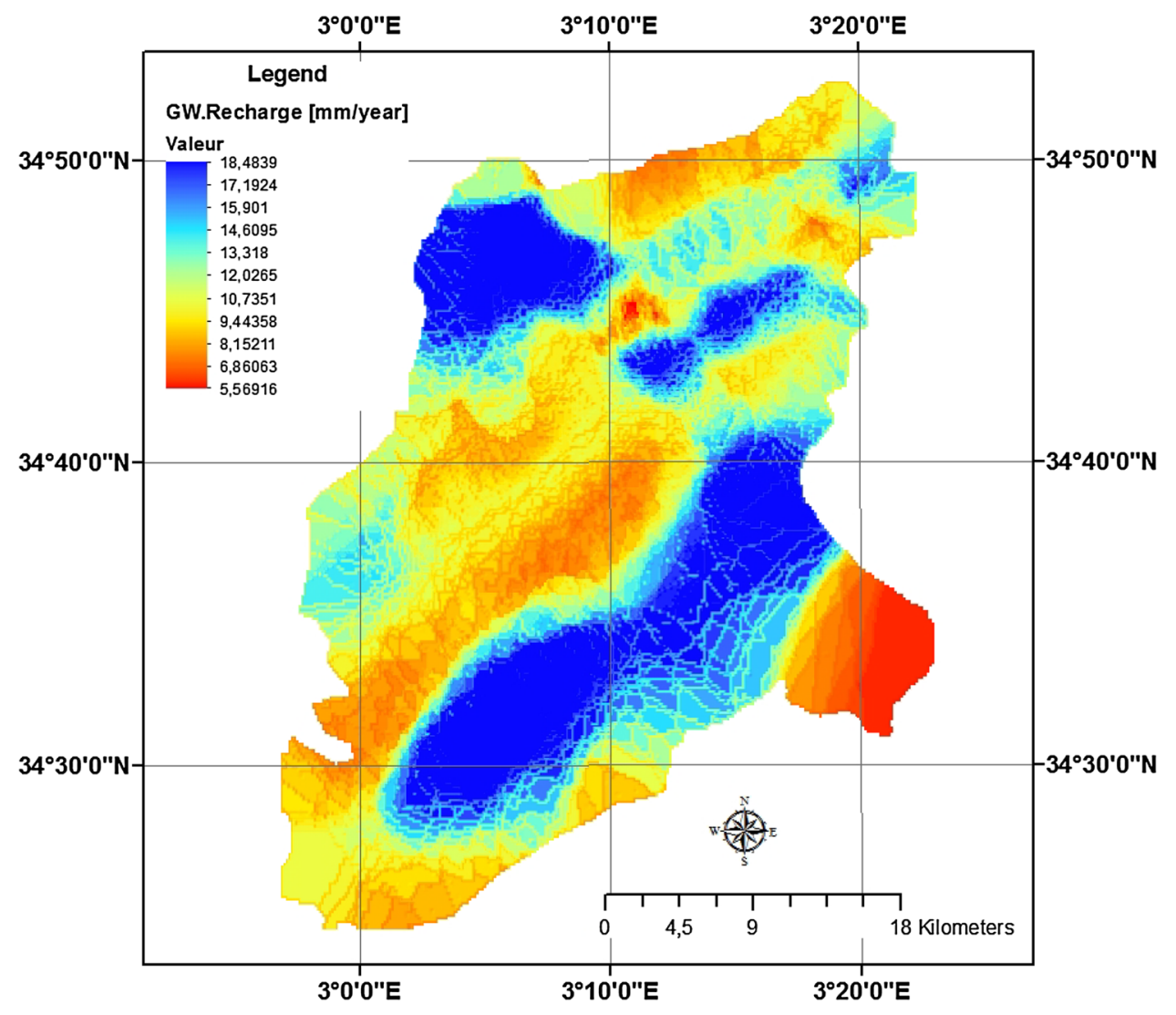

where $\phi$ geological factor characterising the rock, and $P$ annual rainfall given in $\mathrm{mm}$.

The value of some infiltration coefficient $\phi$ is given in Table 2 as given by Banton and Et Bangoy (1997) and Castany (1982, modified).

\section{The hybrid model}

Combination between geological properties of the aquifers (rocks types) and the hydroclimatic data characterizes the semi-aride area and we derive a new mathematical formulae to evaluate the Groundwater recharge in these area.

Many empirical formulas used to explicit the hydrological water budget components underestimate the Recharge (GWR), especially in semi-arid areas.

This makes it difficult to look for other estimation methods, to give an approach value of recharge to sustainably manage the groundwater resources.

Combinations between the empirical formulas make us to formulate a new general model to estimate Groundwater recharge in semi-arid area.
Table 2 Coefficient of infiltration given in \% for different type of Rocks (Banton and Et Bangoy 1997; Castany 1982; modified)

\begin{tabular}{lll}
\hline Type of rock & Coefficient of infiltration $\%$ & Infiltration \\
\hline Gravels & 6 & High \\
Alluvium & 6 & Medium \\
Sandstone & 4 & \\
Sand & 4 & \\
Sandy loam & 4 & \\
Silt & 4 & \\
Clay loam & 4 & \\
Clayey sand & 4 & Low \\
Marl & 4 & \\
Sandy clays & 4 & Very low \\
Limestone & 2 & \\
Crusting & 2 & \\
Dolomite & 2 & \\
Gypsum & 1 & \\
Clays & 1 & \\
Silt & 1 & \\
Soil of Sebkhas & 1 & \\
\hline
\end{tabular}


Fig. 6 Annual variation of ground water recharge estimated by the three models

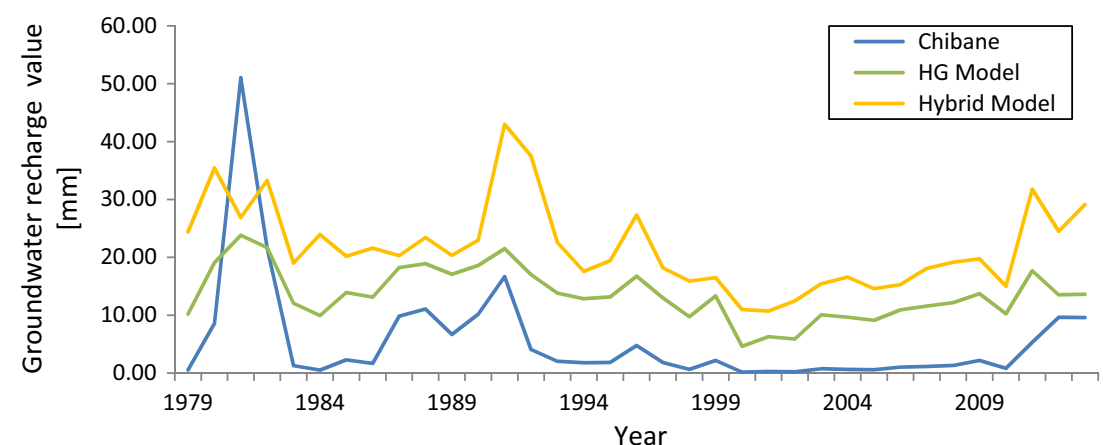

Table 3 Results of chloride mass balance method for the hydrological year of 2013/2014

\begin{tabular}{|c|c|c|c|c|c|c|c|}
\hline Well ID & Cl-well (mg/l) & $T\left({ }^{\circ} \mathrm{C}\right)$ & $\mathrm{pH}$ & $\mathrm{CE}(\mu \mathrm{S} / \mathrm{cm})$ & Cl-rain (mg/l) & Rainfall (mm) & Recharge (mm) \\
\hline$T$ & 197.12 & 20.60 & 7.77 & 622.00 & 3.23 & 300.00 & 4.92 \\
\hline DF1 & 90.76 & 28.30 & 7.84 & 518.00 & 3.65 & 300.00 & 12.06 \\
\hline DF4 bis & 76.58 & 24.60 & 7.96 & 529.00 & 3.55 & 300.00 & 13.91 \\
\hline DF4 & 73.03 & 24.70 & 8.15 & 565.00 & 3.58 & 300.00 & 14.71 \\
\hline DF5bis & 69.49 & 26.60 & 7.94 & 713.00 & 3.43 & 300.00 & 14.81 \\
\hline OSF1 & 44.67 & 16.60 & 8.14 & 822.00 & 3.40 & 300.00 & 22.83 \\
\hline OSF2 & 41.13 & 19.90 & 8.07 & 769.00 & 3.45 & 300.00 & 25.17 \\
\hline OSF3 & 48.22 & 27.00 & 8.13 & 853.00 & 3.47 & 300.00 & 21.59 \\
\hline OSF4 & 44.67 & 37.50 & 8.22 & 744.00 & 3.55 & 300.00 & 23.84 \\
\hline OSF5 & 48.22 & 37.40 & 7.95 & 1860.00 & 3.36 & 300.00 & 20.91 \\
\hline OSF6 & 48.22 & 17.90 & 7.96 & 1906.00 & 3.37 & 300.00 & 20.97 \\
\hline OSF7 & 87.21 & 17.30 & 7.94 & 2030.00 & 3.44 & 300.00 & 11.83 \\
\hline OSF8 & 51.76 & 16.30 & 7.96 & 1365.00 & 3.41 & 300.00 & 19.76 \\
\hline OSF10 & 58.85 & 22.70 & 7.84 & 1165.00 & 3.36 & 300.00 & 17.13 \\
\hline OSF11 & 151.03 & 25.80 & 8.53 & 1214.00 & 3.48 & 300.00 & 6.91 \\
\hline OSF12 & 239.66 & 23.60 & 7.82 & 1057.00 & 3.39 & 300.00 & 4.24 \\
\hline
\end{tabular}

Cl-well [mg/l]: chloride concentration in well in sample, Cl-rain [mg/l]: chloride concentration in rainfall sample

Table 4 Statistic summary of chloride mass balance methods

\begin{tabular}{|c|c|c|c|c|c|c|c|}
\hline Statistics & Cl-well (mg/l) & $T\left({ }^{\circ} \mathrm{C}\right)$ & $\mathrm{pH}$ & $\mathrm{CE}(\mu \mathrm{S} / \mathrm{cm})$ & Cl-rain (mg/l) & Rainfall (mm) & Recharge $(\mathrm{mm})$ \\
\hline Mean & 85.66 & 24.18 & 8.01 & 1045.75 & 3.45 & 300.00 & 15.97 \\
\hline Max & 239.66 & 37.50 & 8.53 & 2030.00 & 3.65 & 300.00 & 25.17 \\
\hline Min & 41.13 & 16.30 & 7.77 & 518.00 & 3.23 & 300.00 & 4.24 \\
\hline Stdv & 57.21 & 6.26 & 0.18 & 489.78 & 0.10 & 0.00 & 6.48 \\
\hline
\end{tabular}

\section{Equation of model}

The new equation developed to evaluate the groundwater recharge $(R)$ is given by the following equation (Eq. 4):

$R=\frac{T^{2}-1}{T^{2}-12 T} \times\left[P-(P-1) \times\left(\frac{\sqrt{T^{2}-1}}{T}\right)\right] \times T^{0.21}$ with $R$ annual average recharge given in (mm), $T$ average annual temperature given in $\left({ }^{\circ} \mathrm{C}\right), P$ average annual rainfall given in $\mathrm{mm}$.

\section{Model of Chibane et al.}

The model of Chibane et al. is a hydrological based model developed and designated to estimate GWR in semi-arid areas. 
Table 5 Result of recharge $[R(\mathrm{~mm})]$ calcul using three models (hybrid model, hydrogeological model, and Chibane et al. models)

\begin{tabular}{|c|c|c|c|c|c|}
\hline Year & $P(\mathrm{~mm})$ & $T\left({ }^{\circ} \mathrm{C}\right)$ & R_Chibane et al. model & R_hybrid_model & R_HG_model \\
\hline 1979 & 654.79 & 15.16 & 26.55 & 20.66 & 22.26 \\
\hline 1980 & 560.93 & 14.64 & 8.58 & 22.61 & 19.07 \\
\hline 1981 & 379.51 & 15.68 & 1.68 & 13.49 & 12.90 \\
\hline 1982 & 637.53 & 15.06 & 21.59 & 21.01 & 21.68 \\
\hline 1983 & 355.25 & 15.61 & 1.28 & 13.37 & 12.08 \\
\hline 1984 & 292.35 & 14.55 & 0.50 & 16.99 & 9.94 \\
\hline 1985 & 409.21 & 15.70 & 2.29 & 13.89 & 13.91 \\
\hline 1986 & 385.65 & 15.34 & 1.66 & 14.89 & 13.11 \\
\hline 1987 & 536.42 & 16.37 & 9.85 & 13.52 & 18.24 \\
\hline 1988 & 555.87 & 15.90 & 11.08 & 15.37 & 18.90 \\
\hline 1989 & 502.37 & 16.18 & 6.67 & 13.65 & 17.08 \\
\hline 1990 & 547.18 & 15.93 & 10.19 & 15.11 & 18.60 \\
\hline 1991 & 632.36 & 14.39 & 16.70 & 26.77 & 21.50 \\
\hline 1992 & 500.49 & 14.31 & 4.08 & 24.20 & 17.02 \\
\hline 1993 & 406.18 & 15.30 & 2.03 & 15.41 & 13.81 \\
\hline 1994 & 377.62 & 16.05 & 1.77 & 12.34 & 12.84 \\
\hline 1995 & 386.63 & 15.71 & 1.82 & 13.49 & 13.15 \\
\hline 1996 & 492.24 & 15.10 & 4.77 & 17.98 & 16.74 \\
\hline 1997 & 382.46 & 15.94 & 1.82 & 12.71 & 13.00 \\
\hline 1998 & 285.96 & 15.82 & 0.65 & 11.66 & 9.72 \\
\hline 1999 & 392.01 & 16.41 & 2.19 & 11.60 & 13.33 \\
\hline 2000 & 136.20 & 16.01 & 0.14 & 9.07 & 4.63 \\
\hline 2001 & 184.62 & 16.69 & 0.26 & 8.58 & 6.28 \\
\hline 2002 & 172.56 & 15.85 & 0.20 & 9.91 & 5.87 \\
\hline 2003 & 296.02 & 16.01 & 0.75 & 11.30 & 10.06 \\
\hline 2004 & 284.25 & 15.64 & 0.61 & 12.13 & 9.66 \\
\hline 2005 & 268.00 & 16.03 & 0.56 & 10.87 & 9.11 \\
\hline 2006 & 321.11 & 16.24 & 1.01 & 11.09 & 10.92 \\
\hline 2007 & 340.84 & 15.70 & 1.12 & 12.83 & 11.59 \\
\hline 2008 & 358.10 & 15.60 & 1.32 & 13.44 & 12.18 \\
\hline 2009 & 403.66 & 15.75 & 2.19 & 13.62 & 13.72 \\
\hline 2010 & 301.08 & 16.17 & 0.81 & 11.00 & 10.24 \\
\hline 2011 & 519.54 & 14.78 & 4.58 & 20.58 & 17.66 \\
\hline 2012 & 396.87 & 15.00 & 6.38 & 16.68 & 13.49 \\
\hline 2013 & 300.18 & 14.54 & 5.01 & 17.21 & 10.21 \\
\hline
\end{tabular}

Table 6 Statistic summary of recharge $(R)$ calcul

\begin{tabular}{lllccc}
\hline & $P(\mathrm{~mm})$ & $T\left({ }^{\circ} \mathrm{C}\right)$ & $R \_$Chibane et al. model & R_hybrid_model & R_HG_model \\
\hline Mean & 398.74 & 15.58 & 4.65 & 14.83 & 13.56 \\
Max & 654.79 & 16.69 & 26.55 & 26.77 & 22.26 \\
Min & 136.20 & 14.31 & 0.14 & 8.58 & 4.63 \\
Stdv & 128.520731 & 0.6077063 & 6.10548797 & 4.24072007 & 4.36970484 \\
\hline
\end{tabular}

it published in 2015. it uses the precipitation and average annual temperature as input. This model underestimates the recharge value for the medium rainfall values ( $p<400 \mathrm{~mm}$ ).
The equation of this model is given by (Eq. 5):

$\mathrm{GWR}_{\mathrm{c}}=0.135 \times\left(\frac{\varphi}{\alpha}\right) \times \mathrm{e}^{0.01047 \times P}$ 


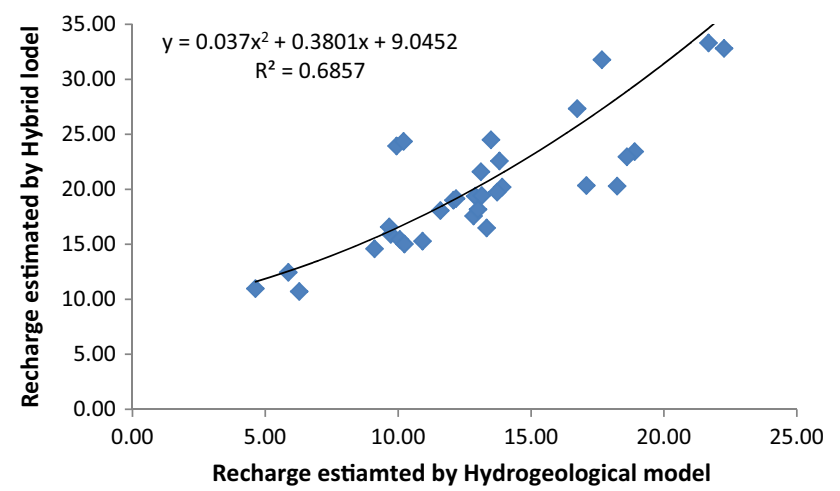

Fig. 7 Correlation between GWR_HG and GWR_HWB

with $\varphi$ and $\alpha$ coefficients depending on temperature, $\mathrm{GWR}_{\mathrm{c}}$ is annual groundwater recharge given in $\mathrm{mm}$, and $P$ average annual precipitation given in $\mathrm{mm}$.

\section{Results and discussion}

The summary of calcul is given in Tables 5 and 6 , the annual variation of groundwater recharge estimated by the three models is illustrated in Fig. 6. As we see the annual mean rainfall approached $390 \mathrm{~mm} /$ year, which characterised the climate of the region; a high precipitation value was observed in the north of the region and it varies from the West to the East. The temperature with an average of $15.6{ }^{\circ} \mathrm{C}$ varies between 14 and $17{ }^{\circ} \mathrm{C}$. The results of chloride mass balance method are shown in Tables 3 and 4 .

According to the results given in Tables 5 and 6 and the graphic results showed in Fig. 6, we see that the variation of groundwater recharge given by the hybrid model is between 14 and $26.77 \mathrm{~mm} /$ year, with a standard deviation $4.24 \mathrm{~mm}$, the value of recharge calculated by the model of Chibane et al. varies between 4 and $26.55 \mathrm{~mm} /$ year with a standard deviation $6.10 \mathrm{~mm}$; in addition the variation of recharge given by the hydrogeological model is between 13.56 and $22.66 \mathrm{~mm} /$ year with a standard deviation $4.36 \mathrm{~mm}$; the two models (Hybrid and hydrogeological) have the same variation with present a best estimation of recharge in the opposite side the model of Chibane present a deficit in the estimation of recharge when the annual rainfall is less than $450 \mathrm{~mm}$ (Vivoni et al. 2009).

The correlation between the values of GWR estimated by the two methods gives a best.

Estimation with a determination coefficient of $\left(R^{2} \approx 0.7\right)$ (Fig. 7).

The average annual ground water recharge given by the two models is between 13 and $15 \mathrm{~mm}$. In the opposite side the mean value of recharge given by the model of Chibane et al. is $4 \mathrm{~mm} /$ year. These results confirm the relationship
Table 7 Error of calcul for each model by tacking the hydrogeological model as a reference

\begin{tabular}{lcc}
\hline Error & Chibane et al. model & Hybrid model \\
\hline Nash & 0.52 & 0.54 \\
MAE & 9.16 & 8.14 \\
RMSE & 9.60 & 9.37 \\
AME & 67.57 & 60.04 \\
\hline
\end{tabular}

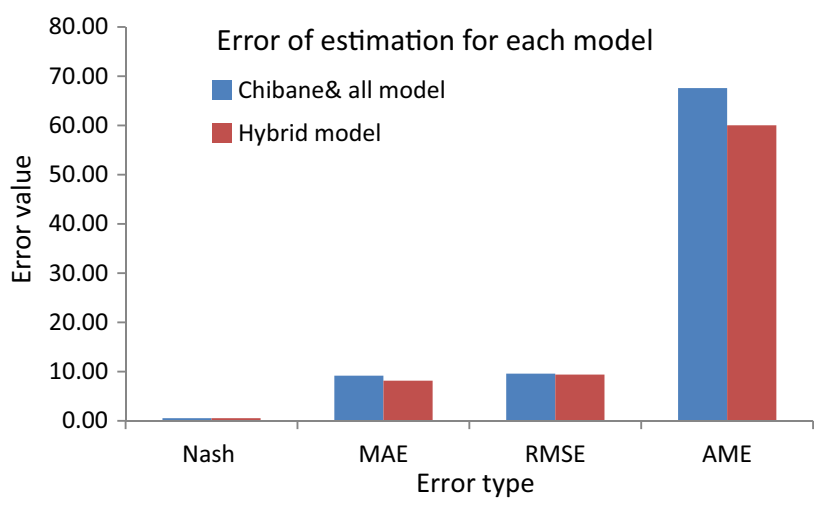

Fig. 8 Graphic show the variation of error of each model

between the new hybrid model designated to the semi-arid area and the hydro-geological model applicated to estimate the groundwater recharge.

Performance of this model was proved using a statistical error mostly used in hydrological modelling as given by Chai and Draxler (2014).

The four error criteria used in this work give a very good estimation of the GWR, which confirm the efficiency of the model. The summary of error calculus are shown in Table 7.

Comparing error of the two model vs the hydrogeological model lets us to take a conclusion that this new hybrid model is better than the model proposed by Chibane and Ali-Rahmani (2015) where RMSE is 9.37, the error of calcul given by the model of Chibane (RMSE $=9.60$ ). The graph in Fig. 8 gives the variation of each error for each model.

The methods of chloride balance give an average annual recharge about $16 \mathrm{~mm} /$ year which is compared to the hydrogeological model and the hybrid model (10 and $17 \mathrm{~mm}$ ). In the opposite side the model of Chibane et al. give $0.54 \mathrm{~mm} /$ year. The $\mathrm{CMB}$ method confirms the results obtained by the two new models (Hybrid model and the Hydrogeological model).

The $2 \mathrm{~d}$ contour plot given in Figs. 9, 10, and 11 give the variation of recharge by the three used model, analysis of this graphic let us to appreciate that the Hybrid model work correctly with the precipitation and the temperature 
Fig. 9 2D contour plot of recharge $[\mathrm{R}(\mathrm{mm})]$ estimated by the Chibane et al. model vs annual rainfall and average annual temperature
Fig. $102 \mathrm{D}$ contour plot of recharge $[\mathrm{R}(\mathrm{mm})]$ estimated by the hydrogeological model vs annual rainfall and average annual temperature
Contour Plot of Chibane \& all model vs $\mathrm{T}\left[{ }^{\circ} \mathrm{C}\right], \mathrm{P}[\mathrm{mm}]$
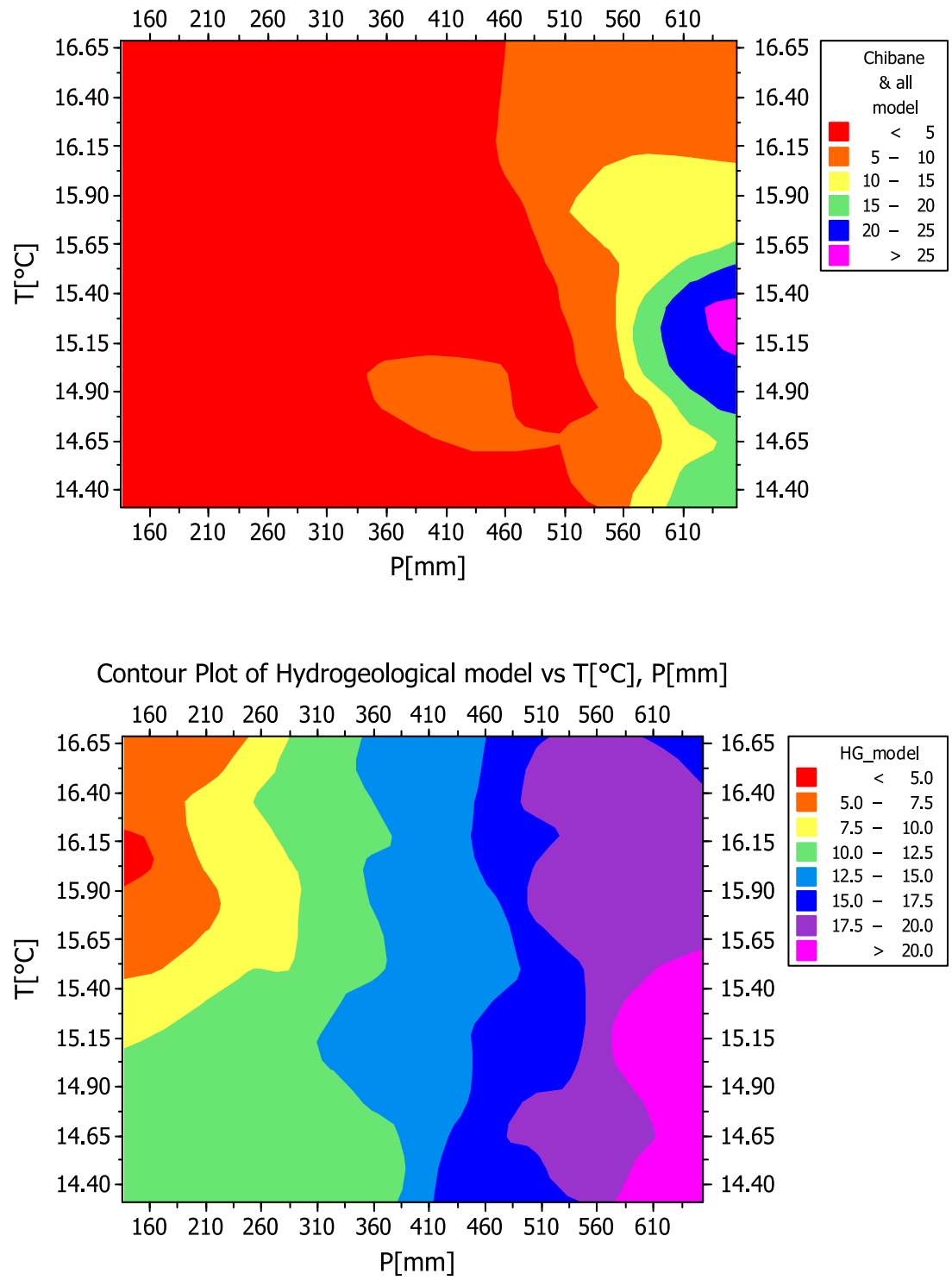

(Fig. 11), in the opposite side the model of Chibane et al. gives a high uncertainty when the amount of precipitation is less than $450 \mathrm{~mm}$ (Fig. 9), the hydrogeological model does not take in the interest the factor of temperature which can deviate in the high temperature values (Fig. 10).

A new recharge class diagram was established to evaluate GWR in semi-arid zones. Three class of groundwater recharge rate are distinguished in function of the annual rainfall in the order of low, medium and high recharge (Fig. 12).

The first class was started from less than $200 \mathrm{~mm} / \mathrm{year}$; where the GWR recharge is less than $15 \mathrm{~mm} / \mathrm{year}$, the second medium class is situated between 450 and $200 \mathrm{~mm}$, the corresponding GWR is located between 15 and $32 \mathrm{~mm} /$ year; the high class started more than $400 \mathrm{~mm} / \mathrm{year}$, the GWR was up and more than $32 \mathrm{~mm} /$ year.
This new classification corresponds to the climate regime and the geological structure of the semi-arid area as explained by Goes (1999).

Isotopic study of the aquifer of region established by Chibane (2010) confirms that the recharge is medium and localised; the age of the groundwater is old, which proves that the recharge velocity is slow.

Limit of model This work is an attempt to find an equation which takes into account the properties of a semiaride area (geological, hydro-climatic characteristics); however, the limit of application of this model is depending on the two parameters (rainfall, and temperature) (Table 8).

In the previous work of Chibane et al. the hydrological model was derived from the hydrological water budget, 
Fig. $112 D$ contour plot of recharge $[\mathrm{R}(\mathrm{mm})]$ estimated by the new hybrid model vs annual rainfall and average annual temperature
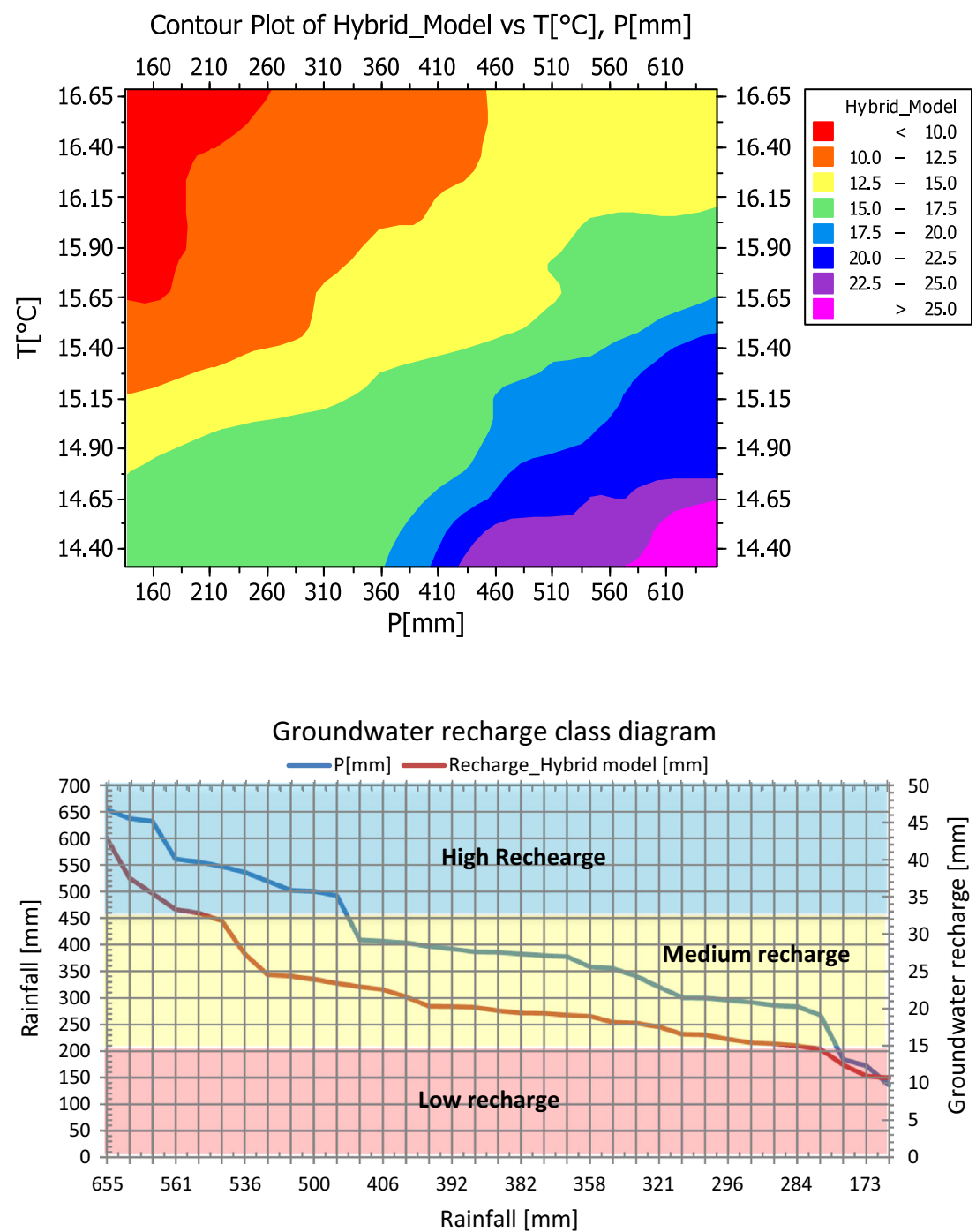

Fig. 12 Diagram shows the class of GWR in function of annual average rainfall
Table 8 Limit of application of model used to evaluate recharge in semi-aride media

\begin{tabular}{lll}
\hline Model & Rainfall $(\mathrm{mm})$ & Temperature $\left({ }^{\circ} \mathrm{C}\right)$ \\
\hline Chibane et al. & $400<P<700$ & $13<T<20$ \\
Hydrogeological model & $P<600$ & - \\
Hybrid model & $100<P<600$ & $13<T<30$ \\
\hline
\end{tabular}

however, this model presents a high deviation in estimation of recharge for low precipitation value $(P<400 \mathrm{~mm})$

The hybrid model and the hydrogeological model work correctly when the average annual precipitation is lower than $600 \mathrm{~mm}$, it work also correctly in arid and semi-arid zones.

The hybrid model was calibrated using chemical tracer methods (Chloride mass balance) to compare the rate of recharge in the study area vs the three models.

\section{Conclusions}

In light of the result a good approximation was approached, and a best estimation of GWR with this new hydrological hybrid model was achieved.

The error types used to test the efficiency of the model confirm that this model gives a best estimation for the GWR in semi-arid area, in our case study of Djelfa (Algeria) where we have tested the model, it gives a very acceptable result. From Fig. 10 our region was located in the medium recharge interval with an average annual recharge between 15 and $32 \mathrm{~mm}$. This new model can be used in all semi-arid areas which have an annual rainfall less than $700 \mathrm{~mm} /$ year.

The application of the chloride mass balance gives us a very interesting result ( $R=16 \mathrm{~mm} /$ year) which is similar to the results obtained by the hybrid model for the same year. The combinations between these results let us to use the new hybrid model with low uncertainty in groundwater recharge assessment. 
Open Access This article is distributed under the terms of the Creative Commons Attribution 4.0 International License (http:// creativecommons.org/licenses/by/4.0/), which permits unrestricted use, distribution, and reproduction in any medium, provided you give appropriate credit to the original author(s) and the source, provide a link to the Creative Commons license, and indicate if changes were made.

\section{References}

Ali Rahmani SE, Chibane B, Hallouz F, Boucefiène F (2015) Study of the relationship between drought index and Groundwater recharge, case of an aquifer in a semi-arid area. In: Proceedings of the international conference on African large river basins hydrology, Hammamet, Tunisia, from 26 October 2015 to 30 October 2015

Banton O, Et Bangoy LM (1997) Hydrogéologie - multiscience environnementale des eaux souterraines, Aupelf Uref, Presses De l'Université Du Québec, p 460

Bonta JV, Müller M (1999) Evaluation of the Glugla method for estimating evapotranspiration and groundwater recharge. Hydrol Sci J 44(5):743-761. doi:10.1080/02626669909492271

Castany G (1982) Principes et méthodes de L'hydrogéologie, Dunod, Paris, France, p 249

Chai T, Draxler RR (2014) Root mean square error (RMSE) or mean absolute error (MAE)? - arguments against avoiding RMSE in the literature. Geosci Model Dev. 7:1247-1250

Chibane B (2010) Hydrogeological and hydrogeochemical gtudy in semi-arid area: case study of the Djelfa region, $\mathrm{PhD}$ thesis in hydrogeology, FSTGAT, USTHB, Algeria
Chibane B, Ali-Rahmani SE (2015) Hydrological based model to estimate groundwater recharge, real evapotranspiration and runoff in semi-arid area, LARHYSS J N ${ }^{\circ} 23$ :Issue 23, ISSN:1112-3680

Foster SSD, Chilton PJ (2003) Groundwater: the processes and global significance of aquifer degradation. Phil Trans R Soc Lond B 358:1957-1972

Goes BJM (1999) Estimate of shallow groundwater recharge in the Hadejia Nguru Wetlands, semi-arid North-Eastern Nigeria. Hydrogeol J 7:294-304 (Springer)

Kinzelbach W, Aeschbach W, Alberich C, Goni IB, Beyerle U, Brunner P, Chiang W-H, Rueedi J, Zoellmann K (2002) A survey of methods for groundwater recharge in arid and semiarid regions. Early warning and assessment report series, UNEP/ DEWA/RS.02-2. United Nations Environment Programme, Nairobi, Kenya, ISBN 92-80702131-3

Nimmo JR, Healy RW, Stonestrom DA (2005) Aquifer recharge. In: Anderson MG, Bear J (eds) Encyclopedia of hydrological science: part 13. Groundwater, vol 4. Wiley, Chichester, pp 2229-2246. doi:10.1002/0470848944.hsa161a. (http://www. mrw.interscience.wiley.com/ehs/articles/hsa161a/frame.html)

Osterkamp WR, Lane LJ, Menges CM (1995) Techniques of groundwater recharge estimates in arid/semi-arid areas, with examples from Abu Dhabi. J Arid Environ 31:349-369

Scanlon BR, Keese KE, Flint AL, Flint LE, Gaye CB, Edmunds WM, Simmers I (2006) Global synthesis of groundwater recharge in semiarid, and arid regions. Hydrol Process 20:3335-3370

Sibanda T, Nonner JC, Uhlenbrook S (2009) Comparison of groundwater recharges estimation methods for the semi-arid Nyamandhlovu area, Zimbabwe. Hydrogeol J 17:1427-1441 (Springer)

Vivoni ER, Aragón CA, Malczynski L, Tidwell VC (2009) Semiarid watershed response in central New Mexico and its sensitivity to climate variability and change. Hydrol Earth Syst Sci 13:715-733 